\title{
Descriptive epidemiology of primary brain and CNS tumors: Results from the Central Brain Tumor Registry of the United States, 1990-1994 ${ }^{1}$
}

\author{
Tanya S. Surawicz², Bridget J. McCarthy, Varant Kupelian, Patti J. Jukich, \\ Janet $M$. Bruner, Faith G. Davis, and the collaborating registries of the \\ Central Brain Tumor Registry of the United States
}

Division of Epidemiology and Biostatistics [T.S.S., B.J.M., V.K., P.J.J., F.G.D.], School of Public Health, University of Illinois at Chicago, IL 60612; and Department of Pathology [J.M.B.], M.D. Anderson Cancer Center, University of Texas, Houston, TX 77030-4095

The Central Brain Tumor Registry of the United States (CBTRUS) obtained 5 years of incidence data (1990-1994)-including reports on all primary brain and CNS tumors-from 11 collaborating state cancer registries. Data were available for 20,765 tumors located in the brain, meninges, and other CNS sites, including the pituitary and pineal glands. The average annual incidence was estimated at 11.5 cases per 100,000 person-years. The higher incidence of tumors in male patients $(12.1$ per 100,000 person-years) than in female patients (11.0 per 100,000 person-years) was statistically significant $(P<0.05)$; the higher incidence in whites $(11.6$ per 100,000 person-years) compared with blacks $(7.8$ per 100,000 person-years) was statistically significant $(P<0.05)$. The most frequently reported histologies were meningiomas $(24.0 \%)$ and glioblastomas $(22.6 \%)$. Higher rates for glioblastomas, anaplastic astrocytomas, oligoden-

Received 22 July 1998, accepted 1 October 1998.

${ }^{1}$ This work was supported by the Pediatric Brain Tumor Foundation of the United States.

${ }^{2}$ Address correspondence and reprint requests to Tanya Surawicz, Division of Epidemiology and Biostatistics (M/C 922), School of Public Health, University of Illinois at Chicago, 2121 West Taylor Street, Chicago, IL 60612-7260.

${ }^{3}$ Abbreviations used are as follows: CBTRUS, Central Brain Tumor Registry of the United States; $\mathrm{Cl}$, confidence interval; NOS, not otherwise specified; RR, relative risk; SEER, Surveillance, Epidemiology, and End Results. drogliomas, anaplastic oligodendrogliomas, ependymomas, mixed gliomas, astrocytomas not otherwise specified, medulloblastomas, lymphomas, and germ cell tumors in male than in female patients were statistically significant $(P<0.05)$, with relative risks $(\mathrm{RR})$ ranging from 1.3 to 3.4. Meningiomas were the only tumors with a significant excess in females $(\mathrm{RR}=0.5)$. We noted higher occurrence rates in whites than in blacks for the following histologies: diffuse astrocytomas, anaplastic astrocytomas, glioblastomas, oligodendrogliomas, ependymomas, mixed gliomas, astrocytomas NOS, medulloblastomas, nerve sheath tumors, hemangioblastomas, and germ cell tumors, with RRs ranging from 1.5 to 3.4. Racial differences in occurrence rates were not observed for predominately benign meningiomas or pituitary tumors. This study represents the largest compilation of data on primary brain and CNS tumors in the United States. Standard reporting definitions and practices must be universally adopted to improve the quality and use of cancer registry data. Neuro-Oncology 1, 14-25, 1999 (Posted to Neuro-Oncology [serial online], Doc. 98-04, January 19, 1999. URL $<$ neuro-oncology.mc.duke.edu>)

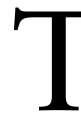
The importance of descriptive data on the full spectrum of primary brain and CNS tumors has been previously recognized (Kurland et al., 1982; Schoenberg et al., 1976). Epidemiologic data in the United States are available for malignant tumors from SEER $^{3}$ and from the North American Association of Central Cancer Registries (Chen et al., 1998; NCI, 
1997). The CBTRUS demonstrated the feasibility of collecting population-based incidence data on the entire spectrum of primary brain and CNS tumors with the publication of a pilot study, which included data from four state registries from the period 1985-1989 (Davis et al., 1996). We have expanded this project to include incidence data from 11 registries for the most recent 5-year period, 1990-1994. Histology-specific incidence rates are presented according to age, race, and sex.

\section{Background}

Most cancer registry data are restricted to primary cancers with a malignant behavior code. For clinicians who diagnose and treat patients with brain and CNS tumors, the distinction between primary benign and malignant tumors is insufficient to predict overall clinical outcome (Davis et al., 1997). Tumor location and histology are also relevant indicators of prognosis. In the United States, the descriptive epidemiology on all primary brain and CNS tumors has been limited to sporadic regional reports from Connecticut and Minnesota in the 1970s (Kurland et al., 1982; Schoenberg et al., 1976) and Los Angeles County in the 1970s and 1980s (Preston-Martin, 1989).

CBTRUS was formed in 1992 to assess the available descriptive data on primary brain and CNS tumors and to develop a centralized population-based database of primary malignant and nonmalignant tumors. The two guiding principles have been (1) to understand how existing surveillance systems provide clinically relevant information on the full spectrum of these unique tumors and (2) to make this information available to the public and, in particular, to neuroscientists. CBTRUS has presented a rationale for including primary brain and CNS tumors of benign and uncertain behavior in tumor registries and made recommendations for standardized reporting definitions, which have been adopted by the International Agency for Research on Cancer (Davis et al., 1997; Parkin et al., 1998). This report represents the largest and most complete compilation of primary brain and CNS tumor data in the United States.

\section{Methods}

CBTRUS obtained incidence data from 11 collaborating state cancer registries, including newly diagnosed cases of benign and malignant primary brain tumors. Data were requested for cases from 1990 to 1994 with a primary tumor at any of the following sites (International Classification of Diseases for Oncology codes): brain (C71.0-C71.9), meninges (C70.0-C70.9), spinal cord, cranial nerves, and other parts of central nervous system (C72.0-C72.9), and pituitary and pineal glands (C75.1-C75.3) (Percy et al., 1990). Data were received with all personal identifiers removed. Yearly population data for each state were obtained from the SEER Web site (Ries et al., 1998), which receives annual population estimates from the U.S. Bureau of the Census. Registry-specific data quality indicators, including percent of cases reported from death certificates, and estimates of duplicate records and their completeness were published elsewhere (Chen et al., 1998). These are overall measures for each cancer registry and percents vary by tumor site.

Accuracy of data submitted to CBTRUS was checked using a modified version of the North American Association of Central Cancer Registries "Call-fordata" metafile from the EDITS software program (EDITS, 1997). Several edits in the metafile were altered to allow tumors of benign or uncertain behavior to pass if the site, morphology, and behavior code combinations were appropriate. Combinations that produced error or warning statements were referred to the state registry for review and correction or confirmation. Most edits could be resolved; however, a small number of reported cases (13) were excluded by our consulting neuropathologist (J.M.B.) because they were coded to histologies not found in the brain or the CNS. Two states (Connecticut and Massachusetts) submitted data in a format that did not allow use of the modified North American Association of Central Cancer Registries metafile. The validity of the reported histology codes from these states, however, were subject to neuropathology review.

The CBTRUS histology groupings use morphology codes from the International Classification of Diseases for Oncology and are broadly grouped according to WHO categories for brain and CNS tumors (Kleihues et al., 1993). Preliminary categories, information about which has been previously published (Davis and Preston-Martin, 1998; Davis et al., 1997), were modified for this analysis to include data from a collaborating registry (Massachusetts) for which behavior code data were unavailable and additional histology codes that appeared in the most recent data. This revised classification scheme is presented in APPENDIX A.

Univariate statistics were used to describe the distribution of tumors by state. Data on behavior codes were unavailable from Massachusetts, and data on diagnostic confirmation were unavailable from Maine. Age-specific and age-adjusted incidence rates, including standard errors and CIs, were estimated using SAS and directly adjusted using the U.S. 1970 population as the standard (Esteve et al., 1994; SAS, 1988). Data by race are presented for whites and blacks only, because population estimates were not readily available for any other race or ethnic category. Childhood tumors were defined as those diagnosed in patients $<20$ years old. Age-specific rates are presented for histology groups with at least 50 total cases. RR by sex and race were calculated by dividing the age-adjusted incidence rates for male patients by those for female patients and by dividing the rates for whites by those for blacks, respectively.

\section{Results}

From 1990 to 1994 , a total of 20,765 tumors were reported by the participating registries, which represented a population of almost 33 million people. The incidence rate of all primary brain and CNS tumors by behavior code for each state is shown in Fig. 1. The 


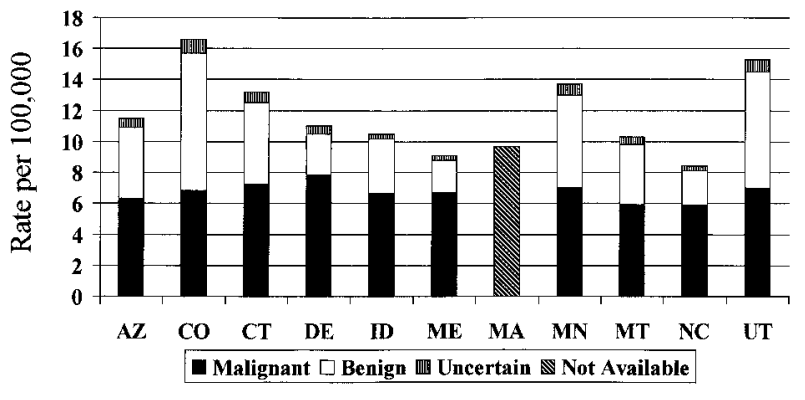

Fig. 1. Annual age-adjusted incidence rates of primary brain and CNS tumors by behavior code (benign, uncertain, or malignant) and state. AZ, Arizona; CO, Colorado; CT, Connecticut; DE, Delaware; ID, Idaho; ME, Maine; MA, Massachusetts; MN, Minnesota; MT, Montana; NC, North Carolina; UT, Utah.

reported percentage of benign tumors ranged from 25.4 to $54.4 \%$, with an average of $40.6 \%$. Annual incidence rates for the malignant tumors, which ranged from 5.9 to 7.8 per 100,000 person-years, varied less than the reported rates for benign tumors (2.1 to 8.9 per 100,000 person-years). Overall, $86.9 \%$ of the tumors were histologically confirmed. The proportion of histologically confirmed tumors ranged from 77.3 to $89.1 \%$ with the exception of one region (Minnesota, 99.8\%), which has a pathology-based cancer reporting system and requires microscopic confirmation for all reported tumors.

The distribution of tumors by site is shown in Fig. 2 . The majority of tumors occurred in the brain with $39 \%$ occurring in the supratentorial region. Other CNS tumors, including the meninges, accounted for $30 \%$, and $9.1 \%$ occurred in the pituitary glands. Only a small fraction $(0.5 \%)$ were reported in the pineal gland.

Incidence rates by sex for the major histology groupings (as outlined in APPENDIX A) are presented in Table 1. The overall incidence rate in male patients is 12.1 per 100,000 person-years; the increased rate compared with female patients (11.0) is statistically significant $(P<0.05)$, as evidenced by the non-overlapping CIs. The percent of unclassified tumors is small $(3 \%)$ and rates are higher for male than female patients. Higher inci-

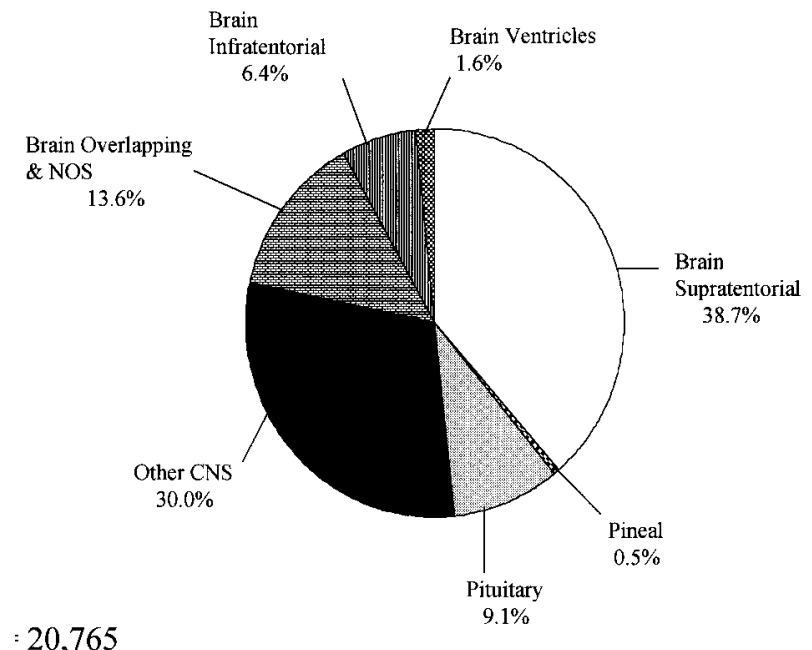

Fig. 2. Distribution of all primary brain and CNS tumors by site, CBTRUS 1990-1994. CBTRUS, Central Brain Tumor Registry of the United States; NOS, not otherwise specified.

dence rates in males compared with females for tumors of neuroepithelial tissue, which include over one-half of all primary brain and CNS tumors, are statistically significant $(P<0.05)$. In contrast, the rates for the next largest category, tumors of the meninges, are higher in female patients than in male patients $(P<0.05)$. Rates for lymphomas and germ cell tumors are also higher in male patients $(P<0.05)$. Sex differences were not apparent for the predominately benign tumors of the cranial and spinal nerves or the sellar region.

The distribution of tumors by detailed histology is presented in Table 2 . The most frequently reported histologies were meningiomas $(24.0 \%)$, glioblastomas $(22.6 \%)$, and astrocytomas $(13.7 \%$; including anaplastic, diffuse, and NOS), which account for over one-half of reported tumors. A large number of astrocytomas $(8.1 \%)$ and malignant gliomas $(2.6 \%)$ were classified as NOS. Patients with meningiomas and glioblastomas had the highest mean age at diagnosis. Patients with the lowest average age at onset were those with the pre-

Table 1. Primary brain and CNS tumor incidence rates by major histology groupings and sex, CBTRUS 1990-1994

\begin{tabular}{|c|c|c|c|c|c|c|c|c|c|}
\hline \multirow[b]{2}{*}{ WHO histology grouping } & \multicolumn{3}{|c|}{ Male patients } & \multicolumn{3}{|c|}{ Female patients } & \multicolumn{3}{|c|}{ Total } \\
\hline & $n$ & Rate & $\mathrm{Cl}$ & $n$ & Rate & $\mathrm{Cl}$ & $n$ & Rate & $\mathrm{Cl}$ \\
\hline Tumors of neuroepithelial tissue & 5,934 & 7.20 & $7.01-7.38$ & 4,701 & 5.05 & $4.90-5.20^{*}$ & 10,635 & 6.04 & $5.93-6.16$ \\
\hline Tumors of cranial and spinal nerves & 633 & 0.74 & $0.68-0.79$ & 724 & 0.77 & $0.72-0.83$ & 1,357 & 0.76 & $0.71-0.80$ \\
\hline Tumors of the meninges & 1,641 & 1.95 & $1.86-2.05$ & 3,616 & 3.51 & $3.39-3.62 *$ & 5,257 & 2.78 & $2.70-2.86$ \\
\hline Lymphomas and hemopoietic neoplasms & 562 & 0.60 & $0.55-0.65$ & 284 & 0.28 & $0.24-0.31 *$ & 846 & 0.43 & $0.40-0.46$ \\
\hline Germ cell tumors and cysts & 98 & 0.14 & $0.11-0.16$ & 29 & 0.04 & $0.03-0.06^{*}$ & 127 & 0.09 & $0.07-0.10$ \\
\hline Tumors of the sellar region & 889 & 1.04 & $0.97-1.11$ & 963 & 1.01 & $0.94-1.08$ & 1,853 & 1.01 & $0.96-1.06$ \\
\hline Local extensions from regional tumors & 21 & 0.03 & $0.01-0.04$ & 24 & 0.02 & $0.01-0.03$ & 45 & 0.02 & $0.02-0.03$ \\
\hline Unclassified tumors & 319 & 0.38 & $0.34-0.42$ & 326 & 0.29 & $0.25-0.32 *$ & 645 & 0.33 & $0.30-0.36$ \\
\hline Total & 10,097 & 12.07 & $11.83-12.31$ & 10,667 & 10.97 & $10.76-11.19 *$ & 20,765 & 11.47 & $11.31-11.63$ \\
\hline
\end{tabular}

Rates are per 100,000 person-years and are age-adjusted using the 1970 U. S. standard population.

${ }^{*} P<0.05$ for difference between male and female patients.

CBTRUS, Central Brain Tumor Registry of the United States; WHO, World Health Organization; $\mathrm{Cl}, 95 \%$ confidence interval. 
Table 2. Distribution and incidence rates of primary brain and CNS tumors by histology, CBTRUS 1990-1994

\begin{tabular}{|c|c|c|c|c|}
\hline Histology & $\begin{array}{c}\text { Total } \\
n\end{array}$ & $\begin{array}{l}\text { Reported } \\
\text { brain tumors (\%) }\end{array}$ & $\begin{array}{c}\text { Mean age at } \\
\text { diagnosis (years) }\end{array}$ & $\begin{array}{l}\text { Rate } \\
( \pm \mathrm{SE})\end{array}$ \\
\hline \multicolumn{5}{|l|}{ Tumors of neuroepithelial tissue } \\
\hline Diffuse astrocytoma (protoplasmic, fibrillary) & 273 & 1.3 & 47 & $0.15(0.01)$ \\
\hline Anaplastic astrocytoma & 885 & 4.3 & 50 & $0.48(0.02)$ \\
\hline Glioblastoma & 4,695 & 22.6 & 62 & $2.60(0.04)$ \\
\hline Pilocytic astrocytoma & 371 & 1.8 & 17 & $0.27(0.01)$ \\
\hline Unique astrocytoma variants & 94 & 0.5 & 35 & $0.06(0.01)$ \\
\hline Oligodendroglioma & 540 & 2.6 & 41 & $0.29(0.01)$ \\
\hline Anaplastic oligodendroglioma & 117 & 0.6 & 46 & $0.07(0.01)$ \\
\hline Ependymoma/anaplastic ependymoma & 420 & 2.0 & 36 & $0.24(0.01)$ \\
\hline Ependymoma variants & 72 & 0.3 & 37 & $0.04(0.01)$ \\
\hline Mixed glioma & 212 & 1.0 & 40 & $0.12(0.01)$ \\
\hline Astrocytoma, NOS & 1,682 & 8.1 & 47 & $0.94(0.02)$ \\
\hline Glioma malignant, NOS & 546 & 2.6 & 46 & $0.31(0.01)$ \\
\hline Choroid plexus & 65 & 0.3 & 22 & $0.04(0.01)$ \\
\hline Neuroepithelial & 34 & 0.2 & 42 & $0.02(0.00)$ \\
\hline Benign and malignant neuronal/glial, neuronal, and mixed & 216 & 1.0 & 24 & $0.13(0.01)$ \\
\hline Pineal parenchymal & 37 & 0.2 & 28 & $0.02(0.00)$ \\
\hline Embryonal/primitive/medulloblastoma & 376 & 1.8 & 14 & $0.26(0.01)$ \\
\hline \multicolumn{5}{|l|}{ Tumors of cranial and spinal nerves } \\
\hline Nerve sheath, benign and malignant & 1,356 & 6.5 & 51 & $0.75(0.02)$ \\
\hline Other tumors of cranial and spinal nerves & 1 & 0.0 & 36 & $0.00(0.00)$ \\
\hline \multicolumn{5}{|l|}{ Tumors of the meninges } \\
\hline Meningioma & 4,989 & 24.0 & 62 & $2.63(0.04)$ \\
\hline Other mesenchymal, benign and malignant & 73 & 0.4 & 39 & $0.04(0.01)$ \\
\hline Hemangioblastoma & 195 & 0.9 & 46 & $0.11(0.01)$ \\
\hline \multicolumn{5}{|l|}{ Lymphomas and hemopoietic neoplasms } \\
\hline Lymphoma & 846 & 4.1 & 54 & $0.43(0.02)$ \\
\hline \multicolumn{5}{|l|}{ Germ cell tumors and cysts } \\
\hline Germ cell tumors, cysts, and heterotopias & 127 & 0.6 & 22 & $0.09(0.01)$ \\
\hline \multicolumn{5}{|l|}{ Tumors of the sellar region } \\
\hline Pituitary & 1,670 & 8.0 & 50 & $0.90(0.02)$ \\
\hline Craniopharyngioma & 183 & 0.9 & 36 & $0.11(0.01)$ \\
\hline \multicolumn{5}{|l|}{ Local extensions from regional tumors } \\
\hline Chordoma/chondrosarcoma & 45 & 0.2 & 60 & $0.02(0.00)$ \\
\hline \multicolumn{5}{|l|}{ Unclassified tumors } \\
\hline Hemangioma & 58 & 0.3 & 41 & $0.03(0.00)$ \\
\hline Neoplasm, unspecified & 579 & 2.8 & 63 & $0.29(0.01)$ \\
\hline Other & 8 & 0.0 & 49 & $0.00(0.00)$ \\
\hline Total & 20,765 & 100.0 & 53 & $11.47(0.08)$ \\
\hline
\end{tabular}

Rates are per 100,000 person-years and age-adjusted using the 1970 U.S. standard population.

CBTRUS, Central Brain Tumor Registry of the United States; NOS, not otherwise specified.

dominately pediatric histologies of medulloblastomas and pilocytic astrocytomas.

Incidence rates by detailed histologies and sex are presented in Table 3. Histologies with higher rates in male than in female patients, where the difference is statistically significant, include glioblastomas, anaplastic astrocytomas, anaplastic oligodendrogliomas, ependymomas, mixed gliomas, astrocytomas NOS, medulloblastomas, and lymphomas, while females have statistically higher rates of meningiomas than males $(P<0.05)$. RRs comparing rates in males to females for histologies with statistically significant differences are shown in Fig. 3.
Incidence rates by race are presented in Table 4. Overall incidence rates of all brain and CNS tumors were higher in whites (11.6 per 100,000 person-years) than in blacks (7.8 per 100,000 person-years), with the difference being statistically significant $(P<0.05)$. Whites had significantly higher rates for several histologies, including diffuse astrocytomas, anaplastic astrocytomas, glioblastomas, oligodendrogliomas, ependymomas, mixed gliomas, astrocytomas NOS, nerve sheath tumors, hemangioblastomas, and germ cell tumors (Fig. 4). Racial differences were not apparent for pituitary adenomas or meningiomas. 
Table 3. Primary brain and CNS tumor incidence rates by histology and sex, CBTRUS 1990-1994

\begin{tabular}{|c|c|c|c|c|c|c|}
\hline \multirow[b]{2}{*}{ Histology } & \multicolumn{3}{|c|}{ Male patients } & \multicolumn{3}{|c|}{ Female patients } \\
\hline & $n$ & Rate & $\mathrm{Cl}$ & $n$ & Rate & $\mathrm{Cl}$ \\
\hline \multicolumn{7}{|l|}{ Tumors of neuroepithelial tissue } \\
\hline Diffuse astrocytoma (protoplasmic, fibrillary) & 138 & 0.16 & $0.13-0.19$ & 135 & 0.15 & $0.12-0.17$ \\
\hline Anaplastic astrocytoma & 496 & 0.57 & $0.52-0.62$ & 389 & 0.40 & $0.36-0.44 *$ \\
\hline Glioblastoma & 2,642 & 3.24 & $3.11-3.36$ & 2,053 & 2.07 & $1.98-2.16^{*}$ \\
\hline Pilocytic astrocytoma & 192 & 0.27 & $0.23-0.31$ & 179 & 0.26 & $0.22-0.30$ \\
\hline Unique astrocytoma variants & 60 & 0.07 & $0.06-0.09$ & 34 & 0.04 & $0.03-0.06$ \\
\hline Oligodendroglioma & 305 & 0.33 & $0.30-0.37$ & 235 & 0.25 & $0.22-0.29 *$ \\
\hline Anaplastic oligodendroglioma & 73 & 0.09 & $0.07-0.11$ & 44 & 0.04 & $0.03-0.06 *$ \\
\hline Ependymoma/anaplastic ependymoma & 237 & 0.28 & $0.25-0.32$ & 183 & 0.20 & $0.17-0.24 *$ \\
\hline Ependymoma variants & 43 & 0.05 & $0.03-0.06$ & 29 & 0.04 & $0.02-0.05$ \\
\hline Mixed glioma & 127 & 0.15 & $0.12-0.17$ & 85 & 0.09 & $0.07-0.11 *$ \\
\hline Astrocytoma, NOS & 931 & 1.09 & $1.02-1.16$ & 751 & 0.80 & $0.74-0.86 *$ \\
\hline Glioma malignant, NOS & 272 & 0.34 & $0.29-0.38$ & 274 & 0.30 & $0.26-0.34$ \\
\hline Choroid plexus & 32 & 0.04 & $0.03-0.05$ & 33 & 0.04 & $0.03-0.06$ \\
\hline Neuroepithelial & 15 & 0.02 & $0.01-0.03$ & 19 & 0.02 & $0.01-0.03$ \\
\hline $\begin{array}{l}\text { Benign and malignant neuronal/glial, } \\
\text { neuronal, and mixed }\end{array}$ & 126 & 0.16 & $0.13-0.19$ & 90 & 0.11 & $0.09-0.13$ \\
\hline Pineal parenchymal & 12 & 0.02 & $0.01-0.03$ & 25 & 0.03 & $0.02-0.04$ \\
\hline Embryonal/primitive/medulloblastoma & 233 & 0.32 & $0.28-0.36$ & 143 & 0.20 & $0.17-0.23^{*}$ \\
\hline \multicolumn{7}{|l|}{ Tumors of cranial and spinal nerves } \\
\hline Nerve sheath, benign and malignant & 632 & 0.73 & $0.68-0.79$ & 724 & 0.77 & $0.72-0.83$ \\
\hline Other & 1 & 0 & NE & 0 & 0 & NE \\
\hline \multicolumn{7}{|l|}{ Tumors of the meninges } \\
\hline Meningioma & 1,499 & 1.79 & $1.70-1.88$ & 3,490 & 3.37 & $3.25-3.48 *$ \\
\hline Other mesenchymal, benign, and malignant & 31 & 0.04 & $0.02-0.05$ & 42 & 0.05 & $0.03-0.06$ \\
\hline Hemangioblastoma & 111 & 0.13 & $0.10-0.15$ & 84 & 0.09 & $0.07-0.11$ \\
\hline \multicolumn{7}{|l|}{ Lymphomas and hemopoietic neoplasms } \\
\hline Lymphoma & 562 & 0.60 & $0.55-0.65$ & 284 & 0.28 & $0.24-0.31 *$ \\
\hline \multicolumn{7}{|l|}{ Germ cell tumors and cysts } \\
\hline Germ cell tumors, cysts, and heterotopias & 98 & 0.14 & $0.11-0.16$ & 29 & 0.04 & $0.03-0.06 *$ \\
\hline \multicolumn{7}{|l|}{ Tumors of the sellar region } \\
\hline Pituitary & 801 & 0.93 & $0.87-1.00$ & 868 & 0.89 & $0.83-0.96$ \\
\hline Craniopharyngioma & 88 & 0.11 & $0.09-0.13$ & 95 & 0.11 & $0.09-0.14$ \\
\hline \multicolumn{7}{|l|}{ Local extensions from regional tumors } \\
\hline Chordoma/chondrosarcoma & 21 & 0.03 & $0.01-0.04$ & 24 & 0.02 & $0.01-0.03$ \\
\hline \multicolumn{7}{|l|}{ Unclassified tumors } \\
\hline Hemangioma & 28 & 0.04 & $0.02-0.05$ & 30 & 0.03 & $0.02-0.04$ \\
\hline Neoplasm, unspecified & 288 & 0.34 & $0.30-0.38$ & 291 & 0.25 & $0.22-0.28 *$ \\
\hline All other & 3 & 0.00 & $0-0.01$ & 5 & 0.01 & $0-0.01$ \\
\hline Total & 10,097 & 12.07 & $11.83-12.31$ & 10,667 & 10.97 & 10.76-11.19* \\
\hline
\end{tabular}

Rates are per 100,000 person-years and are age-adjusted using the 1970 U.S. standard population.

$* P<0.05$ for difference between male and female patients.

CBTRUS, Central Brain Tumor Registry of the United States; CI, 95\% confidence interval; NE, not estimable; NOS, not otherwise specified.

Age-specific incidence rates for the most common histologies are presented in Table 5. The incidence for all brain and CNS tumors increases as age increases with the highest rate in the 75- to 84-year-old age group. Rates for glioblastomas increase sharply with increasing age, with a peak incidence among the 65- to 74-year-olds and a slight decline after age 75. Rates for astrocytomas also increase with age, but the increase is less pronounced than that for glioblastomas. The rates of anaplastic oligodendrogliomas are less related to increasing age with a peak incidence in the 35- to 44year-olds. The incidence of meningiomas increases with age and is highest in the oldest age groups, whereas rates for nerve sheath tumors and pituitary tumors decline slightly after ages 75 and 85 , respectively.

A total of 1,831 tumors $(9 \%)$ were reported in persons $<20$ years old with an incidence rate of 3.8 per 100,000 person-years. The most common pediatric his- 


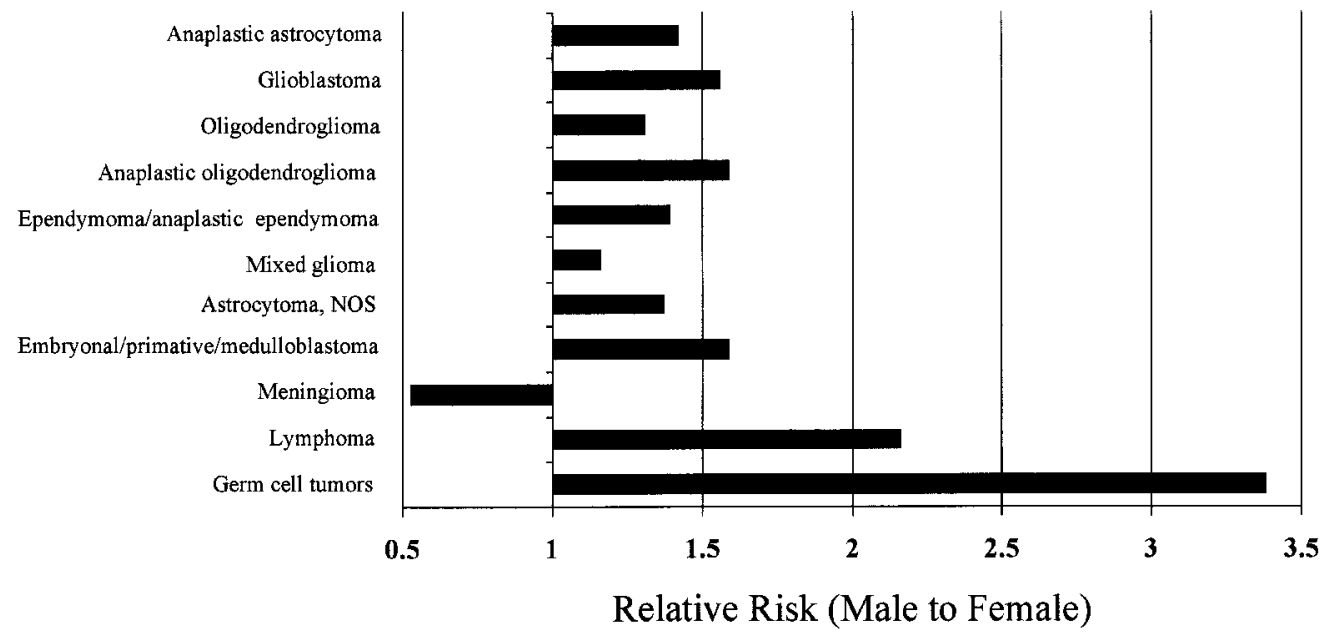

Fig. 3. Relative risks for selected histologies with statistically significant differences in incidence by sex $(P<0.05)$. NOS, not otherwise specified.

tologies included embryonal (medulloblastomas), pilocytic astrocytomas, astrocytomas, NOS, and malignant gliomas (Table 6). These four histologies accounted for $50 \%$ of all pediatric brain and CNS tumors. Overall, rates were higher in male patients, and medulloblastomas had almost a twofold excess in male patients. Age-specific rates for selected pediatric histologies are shown in Table 7. Rates for medulloblastomas and ependymomas were highest in the 0 - to 4-year-olds, whereas the incidence of pilocytic astrocytomas peaks in the 5- to 9-year-old age group.

\section{Discussion}

We report an overall annual incidence rate of $11.5 / 100,000$ person-years for all primary brain and CNS tumors, which is higher than the rate of 9.4/100,000 person-years reported in our pilot study. This increase is likely a result of excluding one registry that participated in the pilot study but did not actively collect benign brain and CNS tumors. The histology-specific estimates reported here are likely to be more accurate than those reported previously because our data editing and classifying procedures have been refined.

The inclusion of data on all primary brain and CNS tumors resulted in a large number of meningiomas, neurilemomas, and pituitary adenomas (predominately benign subtypes), with the proportion of meningiomas reported here larger than previously reported (Mahaley et al., 1989). The incidence rate of meningiomas in male patients (1.8) in our study is identical to that reported by Los Angeles County from 1972-1985, but the incidence rates in female patients (3.4) are higher than those in Los Angeles (2.8) (Preston-Martin, 1989). These differences may reflect variations in reporting, however, because meningiomas were the most frequently underreported tumor in one ascertainment study (Susan T. Gershman, personal communication, 1996).

The male predominance in overall incidence rates and for most histologies confirms findings from previ- ous U.S. studies (Kurland et al., 1982; Preston-Martin, 1989; Walker et al., 1985). An increasing rate of brain lymphomas has been shown to be related to the AIDS epidemic (Cote et al., 1996) and may partially explain the greater occurrence in male patients for this type of brain tumor. Additionally, higher incidence rates of meningiomas in female relative to male patients has been well established (Longstreth et al., 1993; PrestonMartin, 1989). Clinical and population studies have suggested a female preponderance for schwannomas (Chang and Horoupian, 1994; Kuratsu and Ushio, 1996) and pituitary adenomas (Kuratsu and Ushio, 1996; Radhakrishnan et al., 1995; Robinson et al., 1979 ). Incidence rates of nerve sheath tumors from Los Angeles County were comparable in male (0.6) and female (0.7) patients (Preston-Martin, 1989), though slightly lower than the CBTRUS rates (male patients 0.7 , female patients 0.8 ).

Although overall rates for malignant brain tumors are generally reported to be higher among whites than blacks, histologic-specific incidence rates by race are sparse (Annegers and Paleologos, 1994). Incidence rates for all CNS tumors, gliomas, and nerve sheath tumors were higher for whites than blacks in Los Angeles, although the meningioma rates were higher in blacks (Preston-Martin, 1989). An earlier report from the Washington, D.C., metropolitan area disclosed higher proportions of meningiomas and pituitary tumors in blacks compared with whites (Heshmat et al., 1976). In the current study, no racial differences were observed in incidence rates for either meningiomas or pituitary tumors. Rates for whites compared with blacks were two-fold or higher for several histologies, including anaplastic astrocytomas, diffuse astrocytomas, glioblastomas, mixed gliomas, astrocytomas NOS, nerve sheath tumors, hemangioblastomas, and germ cell tumors; the number of cases in blacks was small for some of these histologies. Racial differences in incidence and mortality may be due in part to diagnostic bias (Annegers and Paleologos, 1994), although this likely does not explain all observed variation in rates. 
Table 4. Primary brain and CNS tumor incidence rates by histology and race, CBTRUS 1990-1994

\begin{tabular}{|c|c|c|c|c|c|c|}
\hline \multirow[b]{2}{*}{ Histology } & \multicolumn{3}{|c|}{ White } & \multicolumn{3}{|c|}{ Black } \\
\hline & $n$ & Rate & $\mathrm{Cl}$ & $n$ & Rate & $\mathrm{Cl}$ \\
\hline \multicolumn{7}{|l|}{ Tumors of neuroepithelial tissue } \\
\hline Diffuse astrocytoma (protoplasmic, fibrillary) & 261 & 0.16 & $0.14-0.18$ & 6 & 0.05 & $0.01-0.09 *$ \\
\hline Anaplastic astrocytoma & 826 & 0.50 & $0.46-0.53$ & 27 & 0.21 & $0.13-0.29 *$ \\
\hline Glioblastoma & 4,486 & 2.69 & $2.61-2.77$ & 120 & 1.11 & $0.91-1.32 *$ \\
\hline Pilocytic astrocytoma & 328 & 0.27 & $0.24-0.30$ & 33 & 0.23 & $0.15-0.32$ \\
\hline Unique astrocytoma variants & 86 & 0.06 & $0.05-0.07$ & 6 & 0.05 & $0.01-0.08$ \\
\hline Oligodendroglioma & 504 & 0.30 & $0.28-0.33$ & 19 & 0.16 & $0.09-0.24 *$ \\
\hline Anaplastic oligodendroglioma & 114 & 0.07 & $0.06-0.08$ & 0 & 0 & NE \\
\hline Ependymoma/anaplastic ependymoma & 371 & 0.24 & $0.21-0.27$ & 20 & 0.14 & $0.08-0.21 *$ \\
\hline Ependymoma variants & 69 & 0.04 & $0.03-0.06$ & 1 & 0.01 & NE \\
\hline Mixed glioma & 197 & 0.12 & $0.10-0.14$ & 5 & 0.04 & $0-0.08 *$ \\
\hline Astrocytoma, NOS & 1,586 & 0.98 & $0.93-1.03$ & 49 & 0.36 & $0.26-0.47^{*}$ \\
\hline Glioma malignant, NOS & 488 & 0.31 & $0.28-0.34$ & 44 & 0.35 & $0.24-0.45$ \\
\hline Choroid plexus & 56 & 0.04 & $0.03-0.05$ & 5 & 0.03 & $0-0.06$ \\
\hline Neuroepithelial & 33 & 0.02 & $0.01-0.03$ & 1 & 0.01 & NE \\
\hline Benign and malignant neuronal/glial, neuronal and mixed & 194 & 0.14 & $0.12-0.16$ & 10 & 0.07 & $0.03-0.12$ \\
\hline Pineal parenchymal & 35 & 0.02 & $0.02-0.03$ & 1 & 0.01 & $\mathrm{NE}$ \\
\hline Embryonal/primitive/medulloblastoma & 336 & 0.27 & $0.24-0.30$ & 25 & 0.18 & $0.11-0.24$ \\
\hline \multicolumn{7}{|l|}{ Tumors of cranial and spinal nerves } \\
\hline Nerve sheath, benign, and malignant & 1,240 & 0.76 & $0.71-0.80$ & 26 & 0.23 & $0.14-0.31 *$ \\
\hline \multicolumn{7}{|l|}{ Tumors of the meninges } \\
\hline Meningioma & 4,559 & 2.59 & $2.52-2.67$ & 267 & 2.44 & $2.14-2.74$ \\
\hline Other mesenchymal, benign and malignant & 68 & 0.04 & $0.03-0.06$ & 4 & 0.04 & $0-0.08$ \\
\hline Hemangioblastoma & 182 & 0.11 & $0.10-0.13$ & 6 & 0.04 & $0.01-0.08 *$ \\
\hline \multicolumn{7}{|l|}{ Lymphomas and hemopoietic neoplasms } \\
\hline Lymphoma & 744 & 0.42 & $0.39-0.45$ & 72 & 0.49 & $0.37-0.61$ \\
\hline \multicolumn{7}{|l|}{ Germ cell tumors and cysts } \\
\hline Germ cell tumors, cysts, and heterotopias & 114 & 0.09 & $0.07-0.11$ & 5 & 0.04 & $0-0.07 *$ \\
\hline \multicolumn{7}{|l|}{ Tumors of the sellar region } \\
\hline Pituitary & 1,480 & 0.88 & $0.83-0.92$ & 115 & 0.95 & $0.77-1.13$ \\
\hline Craniopharyngioma & 163 & 0.11 & $0.10-0.13$ & 12 & 0.10 & $0.04-0.15$ \\
\hline \multicolumn{7}{|l|}{ Local extensions from regional tumors } \\
\hline Chordoma/chondrosarcoma & 42 & 0.02 & $0.02-0.03$ & 1 & 0.01 & $\mathrm{NE}$ \\
\hline \multicolumn{7}{|l|}{ Unclassified tumors } \\
\hline Hemangioma & 54 & 0.03 & $0.03-0.04$ & 1 & 0.01 & NE \\
\hline Neoplasm, unspecified & 527 & 0.29 & $0.26-0.31$ & 39 & 0.35 & $0.24-0.46$ \\
\hline Other & 5 & 0.00 & 0-0.01 & 2 & 0 & $\mathrm{NE}$ \\
\hline Total & 19,148 & 11.60 & $11.43-11.77$ & 922 & 7.72 & 7.21-8.24* \\
\hline
\end{tabular}

Rates are per 100,000 person-years and age-adjusted to the 1970 U.S. population.

$* P<0.05$ for difference between whites and blacks.

CBTRUS, Central Brain Tumor Registry of the United States; CI, 95\% confidence interval; NE, not estimable; NOS, not otherwise specified.

Limitations of using cancer registry data have been discussed (Davis et al., 1996). Underreporting of cases, particularly for benign tumors, is a major concern. Previous estimates of underreporting ranged from 30 (Schoenberg et al., 1976) to $100 \%$ (Kurland et al., 1982). A study in Massachusetts disclosed underreporting of all brain and CNS tumors to the central cancer registry; a disproportionate number of those unreported were benign tumors. The shift in health care diagnostic procedures from in-patient to out-patient settings has also had an impact on reporting (Susan T. Gershman, personal communication, 1996). A study of breast cancer case diagnosis in North Carolina revealed that cases identified in a hospital were much more likely to be reported to the central registry than those in a clinic or private practice (Huston et al., 1998). Underreporting of tumors may affect the validity of our estimates, especially for the predominately benign histologies.

Other issues must also be considered, including autopsy rates, case definitions, resolution of duplicate cases, and comparability of populations, before rates can be compared among registries (Chen, 1995). Reg- 


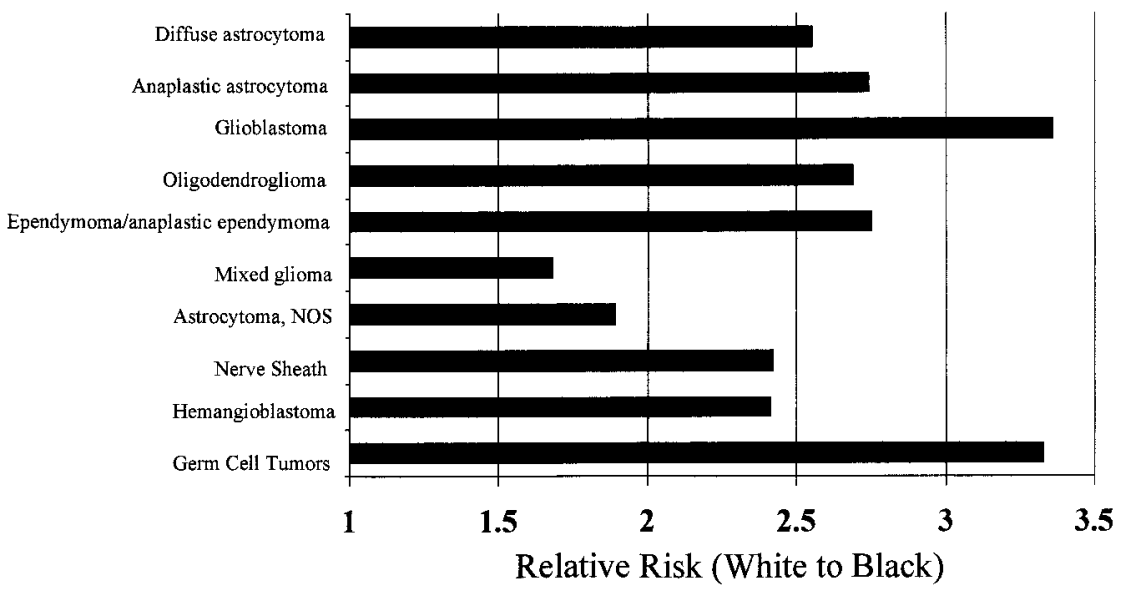

Fig. 4. Relative risks for selected histologies with statistically significant differences in incidence by race $(P<0.05)$. NOS, not otherwise specified. istry practices such as death certificate review to ascertain cases will also affect completeness of reporting (Chen, 1995), although its impact will be greater for certain cancers, such as pancreatic malignancies, and less for selected brain and CNS tumors. The different methods of data reporting in states may also affect the validity of combining state rates (Chen, 1995). Pooling data from several regions, however, allows for detailed descriptive analyses of rare subtypes, such as craniopharyngiomas (Bunin et al., 1997).

Caution must be used when comparing reports from different regions and countries because differences in

Table 5. Primary brain and CNS tumor incidence rates by age at diagnosis, CBTRUS 1990-1994

Age at diagnosis (years)

\begin{tabular}{|c|c|c|c|c|c|c|c|c|}
\hline \multirow[b]{2}{*}{ Histology } & & & & & & & & \\
\hline & 0-19 & $20-34$ & $35-44$ & $45-54$ & $55-64$ & $65-74$ & $75-84$ & $85+$ \\
\hline \multicolumn{9}{|l|}{ Tumors of neuroepithelial tissue } \\
\hline Diffuse astrocytoma & 0.08 & 0.10 & 0.18 & 0.17 & 0.31 & 0.39 & 0.35 & 0.18 \\
\hline Anaplastic astrocytoma & 0.11 & 0.43 & 0.56 & 0.72 & 1.02 & 1.37 & 1.03 & 0.41 \\
\hline Glioblastoma & 0.15 & 0.42 & 1.12 & 3.87 & 8.47 & 12.22 & 10.83 & 4.95 \\
\hline Pilocytic astrocytoma & 0.56 & 0.13 & 0.10 & 0.07 & 0.03 & 0.03 & 0.06 & 0.00 \\
\hline Unique astrocytoma variants & 0.06 & 0.05 & 0.05 & 0.06 & 0.06 & 0.08 & 0.06 & 0.05 \\
\hline Oligodendroglioma & 0.10 & 0.39 & 0.56 & 0.38 & 0.48 & 0.36 & 0.16 & 0.05 \\
\hline Anaplastic oligodendroglioma & 0.01 & 0.06 & 0.08 & 0.17 & 0.12 & 0.10 & 0.07 & 0.00 \\
\hline Ependymoma/anaplastic ependymoma & 0.24 & 0.17 & 0.33 & 0.35 & 0.27 & 0.22 & 0.28 & 0.23 \\
\hline Ependymoma variants & 0.03 & 0.05 & 0.04 & 0.08 & 0.04 & 0.03 & 0.04 & 0.00 \\
\hline Mixed glioma & 0.06 & 0.14 & 0.17 & 0.22 & 0.21 & 0.07 & 0.09 & 0.00 \\
\hline Astrocytoma, NOS & 0.51 & 0.73 & 0.87 & 1.02 & 1.58 & 2.50 & 2.72 & 1.09 \\
\hline Glioma, malignant, NOS & 0.29 & 0.13 & 0.17 & 0.28 & 0.41 & 0.84 & 1.19 & 1.00 \\
\hline Embryonal/primitive/medulloblastoma & 0.56 & 0.15 & 0.09 & 0.08 & 0.01 & 0.02 & 0.01 & 0.00 \\
\hline \multicolumn{9}{|c|}{ Tumors of cranial and spinal nerves } \\
\hline Nerve sheath, benign and malignant & 0.06 & 0.45 & 0.96 & 1.75 & 1.91 & 1.86 & 1.19 & 0.68 \\
\hline \multicolumn{9}{|l|}{ Tumors of the meninges } \\
\hline Meningioma & 0.08 & 0.59 & 1.83 & 4.26 & 6.65 & 11.05 & 13.72 & 13.32 \\
\hline Hemangioblastoma & 0.01 & 0.12 & 0.15 & 0.17 & 0.28 & 0.13 & 0.19 & 0.00 \\
\hline \multicolumn{9}{|l|}{ Lymphomas and hemopoietic neoplasms } \\
\hline Lymphoma & 0.02 & 0.37 & 0.63 & 0.46 & 0.97 & 1.46 & 1.57 & 0.68 \\
\hline \multicolumn{9}{|l|}{ Germ cell tumors } \\
\hline Germ cell & 0.16 & 0.07 & 0.04 & 0.03 & 0.04 & 0.03 & 0.01 & 0.00 \\
\hline \multicolumn{9}{|l|}{ Tumors of the sellar region } \\
\hline Pituitary & 0.13 & 0.86 & 1.21 & 1.31 & 1.96 & 2.24 & 2.24 & 0.77 \\
\hline Craniopharyngioma & 0.13 & 0.06 & 0.09 & 0.10 & 0.13 & 0.16 & 0.19 & 0.05 \\
\hline Total $^{a}$ & 3.79 & 5.84 & 9.63 & 16.08 & 25.79 & 36.35 & 38.91 & 27.14 \\
\hline
\end{tabular}

${ }^{a}$ Refers to all brain tumors, including histologies not listed in this table.

CBTRUS, Central Brain Tumor Registry of the United States; NOS, not otherwise specified. 
T.S. Surawicz et al.: Descriptive epidemiology of brain and CNS tumors

Table 6. Childhood primary brain and CNS tumor incidence rates by sex (ages 0-19 years), CBTRUS 1990-1994

\begin{tabular}{|c|c|c|c|c|c|c|c|c|c|}
\hline \multirow[b]{2}{*}{ Histology } & \multicolumn{3}{|c|}{ Male patients } & \multicolumn{3}{|c|}{ Female patients } & \multicolumn{3}{|c|}{ Total } \\
\hline & $n$ & Rate & $\mathrm{Cl}$ & $n$ & Rate & $\mathrm{Cl}$ & $n$ & Rate & $\mathrm{Cl}$ \\
\hline \multicolumn{10}{|l|}{ Tumors of neuroepithelial tissue } \\
\hline Anaplastic astrocytoma & 32 & 0.13 & $0.09-0.18$ & 20 & 0.09 & $0.05-0.13$ & 52 & 0.11 & $0.08-0.14$ \\
\hline Glioblastoma & 35 & 0.14 & $0.10-0.19$ & 35 & 0.15 & $0.10-0.20$ & 70 & 0.15 & $0.11-0.18$ \\
\hline Pilocytic astrocytoma & 140 & 0.57 & $0.47-0.66$ & 128 & 0.54 & $0.45-0.64$ & 268 & 0.56 & $0.49-0.62$ \\
\hline Ependymoma/anaplastic ependymoma & 67 & 0.26 & $0.19-0.32$ & 47 & 0.18 & $0.13-0.24$ & 114 & 0.22 & $0.18-0.26$ \\
\hline Astrocytoma, NOS & 133 & 0.53 & $0.44-0.62$ & 114 & 0.49 & $0.40-0.58$ & 247 & 0.51 & $0.45-0.57$ \\
\hline Glioma malignant, NOS & 66 & 0.26 & $0.19-0.32$ & 74 & 0.31 & $0.24-0.38$ & 140 & 0.28 & $0.23-0.33$ \\
\hline $\begin{array}{l}\text { Benign and malignant neuronal/glial, } \\
\text { neuronal, and mixed }\end{array}$ & 59 & 0.23 & $0.17-0.29$ & 35 & 0.15 & $0.10-0.19$ & 94 & 0.19 & $0.15-0.23$ \\
\hline Embryonal/primitive/medulloblastoma & 165 & 0.65 & $0.55-0.75$ & 105 & 0.42 & $0.34-0.50 *$ & 270 & 0.54 & $0.48-0.60$ \\
\hline \multicolumn{10}{|l|}{ Germ cell tumors } \\
\hline Germ cell & 55 & 0.23 & $0.17-0.30$ & 20 & 0.08 & $0.05-0.12 *$ & 75 & 0.16 & $0.12-0.20$ \\
\hline \multicolumn{10}{|l|}{ Tumors of the sellar region } \\
\hline Craniopharyngioma & 32 & 0.13 & $0.08-0.18$ & 32 & 0.14 & $0.09-0.18$ & 64 & 0.13 & $0.10-0.17$ \\
\hline Total $^{a}$ & 992 & 3.98 & $3.73-4.23$ & 839 & 3.53 & $3.29-3.77$ & 1,831 & 3.76 & 3.59-3.93 \\
\hline
\end{tabular}

Rates are per 100,000 person-years and are age-adjusted using the 1970 U.S. standard population.

${ }^{a}$ Refers to all childhood brain tumors, including histologies not listed in this table.

$* P<0.05$ for difference between male and female patients.

CBTRUS, Central Brain Tumor Registry of the United States; CI, 95\% confidence interval; NOS, not other wise specified.

definitions and reporting practices may explain some or most of the variation. The pilot study showed statistically significant variation in incidence rates across regions. Our experience with the individual registries shows that registries that collect data on benign brain and CNS tumors do not follow the same practices. For example, Utah collects data on benign tumors of the brain and meninges, but does not include data on benign tumors of the spinal cord or acoustic nerve in their registry (personal communication, Sue Ann
McFadden, CTR, Utah Cancer Registry, June 1998). Minnesota does not include microscopically unconfirmed tumors; however, Minnesota's reported incidence rate is higher than that from other states that do include these tumors. This suggests incomplete case findings in other registries or higher rates of microscopic confirmation in Minnesota. Regional variation in incidence rates observed here, especially for benign tumors, illustrates the need for a standard definition of reportable cases and standard reporting criteria to

Table 7. Childhood primary brain and CNS tumor incidence rates by age at diagnosis (ages 0-19 years), CBTRUS 1990-1994

\begin{tabular}{|c|c|c|c|c|}
\hline \multirow[b]{2}{*}{ Histology } & \multicolumn{4}{|c|}{ Age at diagnosis (years) } \\
\hline & $0 \_4$ & $5-9$ & $10-14$ & $15-19$ \\
\hline \multicolumn{5}{|l|}{ Tumors of neuroepithelial tissue } \\
\hline Anaplastic astrocytoma & 0.06 & 0.10 & 0.15 & 0.13 \\
\hline Glioblastoma & 0.10 & 0.08 & 0.21 & 0.19 \\
\hline Pilocytic astrocytoma & 0.52 & 0.68 & 0.57 & 0.45 \\
\hline Ependymoma/anaplastic ependymoma & 0.51 & 0.19 & 0.15 & 0.08 \\
\hline Astrocytoma, NOS & 0.58 & 0.50 & 0.64 & 0.32 \\
\hline Glioma malignant, NOS & 0.43 & 0.40 & 0.21 & 0.10 \\
\hline Benign and malignant neuronal/glial, neuronal, and mixed & 0.29 & 0.15 & 0.23 & 0.11 \\
\hline Embryonal/primitive/medulloblastoma & 0.85 & 0.78 & 0.32 & 0.25 \\
\hline \multicolumn{5}{|l|}{ Germ cell tumors } \\
\hline Germ cell & 0.09 & 0.10 & 0.23 & 0.21 \\
\hline \multicolumn{5}{|l|}{ Tumors of the sellar region } \\
\hline Craniopharyngioma & 0.11 & 0.19 & 0.16 & 0.07 \\
\hline Total $^{a}$ & 4.40 & 3.80 & 3.70 & 3.21 \\
\hline
\end{tabular}

${ }^{a}$ Refers to all childhood brain tumors, including histologies not listed in this table.

CBTRUS, Central Brain Tumor Registry of the United States; NOS, not otherwise specified. 
ensure complete reporting and allow for comparisons across regions.

Regional differences in case reporting, including differential use of diagnostic tools and possible regional differences in neuropathology practice, must also be considered. A previous report suggested that Connecticut pathologists were more likely to classify a tumor as a glioblastoma rather than astrocytoma when com-

Appendix A. CBTRUS brain and CNS tumor histology groupings, 1998 revision

\begin{tabular}{|c|c|}
\hline \multicolumn{2}{|l|}{ Tumors of neuroepithelial tissue } \\
\hline Diffuse astrocytoma (protoplasmic, fibrillary) & 9410,9420 \\
\hline Anaplastic astrocytoma & 9401,9411 \\
\hline Glioblastoma & $9440,9441,9442$ \\
\hline Pilocytic astrocytoma & 9421 \\
\hline Unique astrocytoma variants & $9383,9384,9424$ \\
\hline Oligodendroglioma & 9450 \\
\hline Anaplastic oligodendroglioma & 9451,9460 \\
\hline Ependymoma/anaplastic ependymoma & 9391, 9392, 9393 \\
\hline Ependymoma variants & 9394 \\
\hline Mixed glioma & 9382 \\
\hline Astrocytoma, NOS & 9400 \\
\hline Glioma Malignant, NOS & 9380 \\
\hline Choroid plexus & 9390 \\
\hline Neuroepithelial & $9381,9423,9430$ \\
\hline Benign and malignant neuronal/glial, neuronal and mixed & 8680, 9364, 9490, 9491, 9500, 9505, 9506 \\
\hline Pineal parenchymal & 9360, 9361, 9362 \\
\hline Embryonal/primitive/medulloblastoma & $9443,9470,9471,9472,9473,9502,9503$ \\
\hline \multicolumn{2}{|l|}{ Tumors of cranial and spinal nerves } \\
\hline Nerve sheath, benign and malignant & $9540,9550,9560,9570$ \\
\hline Other & 9562 \\
\hline \multicolumn{2}{|l|}{ Tumors of the meninges } \\
\hline Meningioma & 9530, 9531, 9532, 9533, 9534, 9537, 9538 \\
\hline Other mesenchymal, benign and malignant & $\begin{array}{l}8800,8801,8803,8810,8850,8861,8900, \\
8910,8990,9133,9150,9240,9480,9481,9536\end{array}$ \\
\hline Hemangioblastoma & 9161,9535 \\
\hline \multicolumn{2}{|l|}{ Lymphomas and hemopoietic neoplasms } \\
\hline Lymphoma & $\begin{array}{l}9590,9591,9594,9595,9640^{\mathrm{a}}, 9650,9652, \\
9663,9670,9671,9672,9675,9680,9681,9682, \\
9683,9684,9685,9686,9687,9690,9691,9693, \\
9695,9696,9698,9702,9707,9711,9714,9720, \\
9731,9766,9827,9970\end{array}$ \\
\hline \multicolumn{2}{|l|}{ Germ cell tumors and cysts } \\
\hline Germ cell tumors, cysts, and heterotopias & $\begin{array}{l}8020,9060,9061,9064,9071,9080,9081, \\
9084,9085\end{array}$ \\
\hline \multicolumn{2}{|l|}{ Tumors of the sellar region } \\
\hline Pituitary & $\begin{array}{l}8040,8140,8146,8260,8270,8271,8280 \\
8281,8290,8300,8323,8333\end{array}$ \\
\hline Craniopharyngioma & 9350 \\
\hline \multicolumn{2}{|l|}{ Local extensions from regional tumors } \\
\hline Chordoma/chondrosarcoma & 9370 \\
\hline \multicolumn{2}{|l|}{ Unclassified tumors } \\
\hline Hemangioma & $9120,9121,9130,9131$ \\
\hline Neoplasm, unspecified & $8000,8001,8002,8003$ \\
\hline Other & 8720,9580 \\
\hline
\end{tabular}

aWHO, 1976.

The histology codes included here were those reported to CBTRUS. This APPENDIX does not include all possible valid histology codes.

CBTRUS, Central Brain Tumor Registry of the United States; ICD-O, International Classification of Diseases for Oncology; NOS, not other wise specified. 
pared with other SEER registries (Velema and Percy, 1987). A pathology review study that will provide information on diagnostic validity is currently in progress in Connecticut.

Classification of histologies is often problematic, especially for brain and central nervous system tumors. Numerous histologic categories and a lack of consensus on diagnostic criteria for certain subtypes, such as oligodendrogliomas, make consistent classification of these tumors difficult. Another factor that increases the difficulty of accurate classification is the cellular heterogeneity of brain tumors, especially gliomas, and the tendency of biopsy procedures to produce very small tissue fragments for histologic examination. The large number $(10.7 \%)$ of NOS astrocytomas and malignant gliomas in these data suggest that specific categories may be underreported. Advances in understanding the genetic alterations in brain tumors and subclassifying histologic categories based on these genetic alterations (i.e., primary vs. secondary glioblastomas) and an increase in the number of cases being diagnostically confirmed may permit a more meaningful classification of brain tumors (Louis and Gusella, 1995). In addition, identifying homogenous subpopulations will help to determine etiologic risk factors associated with disease initiation or progression. Despite usage of the most current histologic or molecular techniques, classifying all these heterogeneous tumors consistently or accurately, based on small biopsy fragments, may be impossible.

Issues of complete case identification and reliable classification remain problematic though there may be some consensus on a national level to move toward complete reporting of all primary brain and CNS tumors (Davis et al., 1996). The brain tumor subcommittee organized by the Centers for Disease Control and Prevention is evaluating the collection of primary brain and CNS tumor data in the U.S. cancer registry system. Although imperfect, these data again demonstrate the importance of histology-specific information, since differences in age, sex, and race may have etiologic significance. In addition, they allow us to estimate the expected number of cases for selected populations. Continued improvements in case identification and registration will improve the quality of these data and provide a better basis for the development of clinical and etiologic studies with which to improve prognosis and determine histology-specific etiologic factors. Only then can we begin to discuss prevention strategies for these intractable tumors.

\section{Acknowledgments}

The authors thank Marsha Rubin, Dr. William Paul, Dr. Greta Bunin, Dr. Susan Preston-Martin, and Dr. Margaret Wrensch for reviewing the manuscript and Jay Hurh for preparing the figures.

The Central Brain Tumor Registry of the United States (CBTRUS) includes Georgia Yee, Arizona Cancer Registry; Robin Bott, Colorado Central Cancer Registry; Anthony Polednak, Connecticut Tumor Registry; Carol Marker, Delaware State Tumor Registry; Stacey Carson, Cancer Data Registry of Idaho; Melanie Lanctot, Maine Cancer Registry; Susan Gershman, Massachusetts Cancer Registry; Sally Bushhouse, Minnesota Cancer Surveillance System; Debbi Hellhake, Montana Central Tumor Registry; Rebecca Martin, North Carolina Central Cancer Registry; and Rosemary Dibble, Utah Cancer Registry.

\section{References}

Annegers, J.F., and Paleologos, N. (1994) Intracranial neoplasia. In: Gorelick, P.B., and Alter, M., (Eds.), Handbook of Neuroepidemiology. New York: Marcel Dekker, pp. 295-313.

Bunin, G., Surawicz, T.S., Witman, P.A., Preston-Martin, S., Davis, F., and Bruner, J.M. (1997) The descriptive epidemiology of craniopharyngioma. Neurosurg. Focus 3, 1-5.

Chang, Y., and Horoupian, D.S. (1994) Pathology of benign brain tumors. In: Morantz, R.A., and Walsh, J.W. (Eds.), Brain Tumors: An Encyclopedic Text. New York: Marcel Dekker, pp. 19-44.

Chen, V.W. (1995) Should we or shouldn't we compare incidence rates among registries? In: Howe, H.L. (Ed.), Cancer Incidence in North America, 1988-1991. Sacramento: North American Association of Central Cancer Registries, pp. V1-V6.

Chen, V.W., Wu, X.C., and Andrews, P.A. (Eds.) (1998) Cancer in North America, 1990-1994, Vol. 1. Sacramento: North American Association of Central Cancer Registries.

Cote, T.R., Manns, A., Hardy, C.R., Yellin, F.J., Hartge, P., and the AIDS/Cancer Study Group (1996) Epidemiology of brain lymphoma among people with or without acquired immunodeficiency syndrome. J. Natl. Cancer Inst. 88, 675-679.

Davis, F.G., and Preston-Martin, S. (1998) Epidemiology: Incidence and survival. In: Bigner, D.D., McLendon, R.E., and Bruner, J.M. (Eds.), Russell and Rubinstein's Pathology of the Nervous System, Vol. 1. London: Arnold, pp. 5-45.
Davis, F.G., Malinski, N., Haenszel, W., Chang, J., Flannery, J., Gershman, S., Dibble, R., and Bigner, D.D. (1996) Primary brain tumor incidence rates in four United States regions, 1985-1989: A pilot study. Neuroepidemiology 15, 103-12.

Davis, F.G., Bruner, J.M., and Surawicz, T.S. (1997) The rationale for standardized registration and reporting of brain and central nervous system tumors in population-based cancer registries. Neuroepidemiology 16, 308-316.

EDITS [computer program]. (1997) Version 2.00. Atlanta, Ga: Centers for Disease Control and Prevention.

Esteve, J., Benhamou, E., and Raymond, L. (1994) Statistical Methods in Cancer Research, Vol. IV. Lyon, France: International Agency for Research on Cancer, World Health Organization.

Heshmat, M.Y., Kovi, J., Simpson, C., Kennedy, J., and Fan, K.J. (1976) Neoplasms of the central nervous system. Incidence and population selectivity in the Washington DC, metropolitan area. Cancer 38, 2135-2142.

Huston, S.L., Dickinson, C., Herman, D., Conlisk, E., and Lengerich, E.J. (1998) Completeness of female breast cancer case ascertainment by the North Carolina Central Cancer Registry. J. Registry Manage. 25, 56-59.

Kleihues, P., Burger, P.C., and Scheithauer, B.W. (1993) The new WHO classification of brain tumours. Brain Pathol. 3, 255-268.

Kuratsu, J., and Ushio, Y. (1996) Epidemiological study of primary intracranial tumors: A regional survey in Kumamoto Prefecture in the southern part of Japan. J. Neurosurg. 84, 946-950. 
T.S. Surawicz et al.: Descriptive epidemiology of brain and CNS tumors

Kurland, L.T., Schoenberg, B.S., Annegers, J.F., Okazaki, H., and Molgaad, C.A. (1982) The incidence of primary intracranial neoplasms in Rochester, Minnesota 1935-1977. Ann. N. Y. Acad. Sci. 381, 6-16.

Longstreth, W.T., Jr., Dennis, L.K., McGuire, U.M., Drangsholt, M.T., and Koepsell, T.D. (1993) Epidemiology of intracranial meningioma. Cancer 72, 639-648.

Louis, D.N., and Gusella, J.F. (1995) A tiger behind many doors: Multiple genetic pathways to malignant glioma. Trends Genet. 11, 412-415.

Mahaley, M.S., Jr., Mettlin, C., Natarajan, N., Laws, E.R., Jr., and Peace, B.B. (1989) National survey of patterns of care of brain-tumor patients. J. Neurosurg. 71, 826-836.

National Cancer Institute [CD-ROM] (1997) Surveillance, Epidemiology, and End Results (1973-1994). Bethesda, Md: U.S. Department of Health and Human Services.

Parkin, D.M., Shanmugaratnam, K., Sobin, L., Ferlay, J., and Whelan, S.I. (1998) Histological groups for comparative studies. International Agency for Research on Cancer (IARC) Technical Report No. 31, World Health Organization. Lyon: France.

Percy, C., Van Holten, V., and Muir, C.M. (Eds.) (1990) International Classification of Diseases for Oncology. Second edition. Geneva, Switzerland: World Health Organization.

Preston-Martin, S. (1989) Descriptive epidemiology of primary tumors of the brain, cranial nerves, and cranial meninges in Los Angeles County. Neuro- epidemiology 8, 283-295.

Radhakrishnan, K., Mokri, B., Parisi, J.E., O'Fallon, W.M., Sunku, J., and Kurland, L.T. (1995) The trends in incidence of primary brain tumors in the population of Rochester, Minnesota. Ann. Neurol. 37, 67-73.

Robinson, N., Beral, V., and Ashley, J.S. (1979) Incidence of pituitary adenoma in women. Lancet 2, 630. (Letter)

SAS [computer program] (1988), Version 6. Cary, NC: SAS Institute.

Schoenberg, B.S., Christine, B.W., and Whisnant, J.P. (1976) The descriptive epidemiology of primary intracranial neoplasms: The Connecticut experience. Am. J. Epidemiol. 104, 499-510.

Ries, L.A.G., Kosary, C.L., Hankey, B.F., Miller, B.A., and Edwards, B.K. (Eds.) (1998) SEER Cancer statistics review 1973-1995 (preliminary edition). SEER Web site. Last updated June 19, 1998; cited November 11, 1997. World Wide Web URL: <http://www-seer.ims.nci.nih.gov/>.

Velema, J.P., and Percy, C.L. (1987) Age curves of central nervous system tumor incidence in adults: Variation of shape by histologic type. J. Natl. Cancer Inst. 79, 623-629.

Walker, A.E., Robins, M., and Weinfeld, F.D. (1985) Epidemiology of brain tumors: The national survey of intracranial neoplasms. Neurology 35 , 219-226.

World Health Organization (1976) ICD-O: International Classification of Diseases for Oncology, 1st edition. Geneva, Switzerland: World Health Organization. 